\title{
OPTIMALISASI PENGEMBANGAN KAWASAN WISATA BUKIT KOREA DI DESA DOPANG KECAMATAN GUNUNG SARI KABUPATEN LOMBOK
}

\author{
Rianto Derita Jaya1, Miftahul Rizki Lestari2, Ridha Surgana3, Nanda Dicky Prabowo4, Himmatul \\ Laily5, Dimas Akbar Juliawan6, Annisa7, M. Yamin Al Asyir8, Reta Yunita9, Salsabila Luki Sucia10 \\ 1,2,5 Fakultas Pertanian \\ 3,7,9,10Fakultas Keguruan dan IImu Pendidikan \\ 4Fakultas Hukum \\ ${ }_{6}$ Fakultas Teknik \\ ${ }_{8}$ Fakultas Peternakan \\ *Co-Author : deritajayarianto@gmail.com
}

\begin{abstract}
ABSTRAK. Pengembangan kawasan wisata merupakan salah satu sektor kegiatan yang mampu mendorong aspek perekonomian terutama untuk peningkatan pendapatan masyarakat, dalam hal ini masyarakat desa Dopang, kecamatan Gunungsari, Kabupaten Lombok Barat. Desa Dopang adalah salah satu desa otonom dengan salah satu potensi utama pada bidang Pariwisata yaitu wisata alam bukit Korea yang masih baru dikembangkan di Desa Dopang, Kecamatan Gunungsari, Kabupaten Lombok Barat. Berdasarkan hasil observasi dalam rangka penyelenggaraan kegiatan KKN-pemberdayaan Universitas Mataram Tahun 2019, ditemukan masalah bahwa masih kurangnya pengelolaan fasilitas prasarana baik secara fisik dan non fisik, serta kurangnya daya Tarik unggulan. Permasalahan pengembangan Wisata Bukit Korea ini dikarenakan kurangnya kesadaran masyarakat dan lembaga terkait di Desa Dopang yaitu dalam mengembangkan dan mempromosikan wilayah tersebut. Metode yang digunakan dalam optimalisasi pengembangan kawasan wisata Bukit Korea didasarkan pada keberhasilan obyek wisata, ketersediaan SDM pengelola, manfaat keberadaan wisata aspek finansial, dan dampak sosialnya. Hasil yang dicapai pada kegiatan ini adalah penataan kawasan wisata yang lebih baik, pemantapan Kelembagaan pengelola wisata yaitu Karang taruna dan Pokdarwis, pengelolaan wisata yang tepat, promosi wisata melalui akun-akun media sosial secara online, serta pengembangan SDL sebagai penunjang keberhasilan pengembangan wisata, dan pembelajaran barbasis wisata dan alam melibatkan anak sekolah dasar Desa Dopang sebagai Generasi penerus dalam pengembangan kawasan Wisata Di Desa dopang, Kecamatan Gunungsari, Kabupaten Lombok Barat.
\end{abstract}

Kata Kunci: pariwisata, pengembangan, optimalisasi.

ABSTRACT. Development of tourist areas is one of the activities sector that can encourage economic aspects, especially for the increase of public income, in this case the community of Dopang village, Gunungsari District, West Lombok Regency. Dopang Village is one of the autonomous villages with one of the main potentials in tourism of Korea's new Hill nature tourism which is still newly developed in Dopang village, Gunungsari District, West Lombok Regency. Based on the results of observation in the course of organizing the activities of the University of Mataram-Empowerment in 2019, there was a problem that still lack of infrastructure management both physically and non physical, and lack of superior attraction. The problem of development of Bukit Korea tourism is due to lack of public awareness and related institutions in Dopang village in developing and promoting the region. The method used in optimizing the development of Bukit Korea tourist area is based on the success of tourism objects, availability of human 
resources managers, benefits of tourism existence financial aspects, and social impacts. The results of this activity are the arrangement of better tourist areas, development of tourism management institutions, namely Karang Taruna and Pokdarwis, appropriate travel arrangements, travel promotion through social media accounts online, as well as developing SDL as supporting the success of tourism development, and the learning of travel and nature base of the primary school children Dopang Village as the successor generation in the development of the tourism area in Dopang village , Gunungsari District, West Lombok Regency.

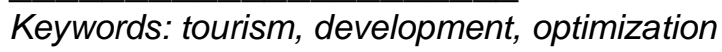

\section{PENDAHULUAN}

Pariwisata merupakan suatu keseluruhan elemen-elemen terkait yang didalamnya terdiri dari wisatawan, daerah tujuan wisata, sumberdaya Manusia, sumberdaya alam dan Lokal,industri dan lain sebagainya yang merupakan kegiatan pariwisata. Pariwisata saat ini menjadi andalan utama sumber devisa untuk meningkatkan keberhasilan ekonomi masyarakat dan ekonomi daerah.

Desa yang baru memulai pengembangan desa wisata, pada umumnya memiliki beban dan tanggungjawab yang besar, serta pengalaman dan cara pengelolaan wisata, untuk itu perlunya perhatian yang lebih serius terhadap Desa dan masyarakat dalam pengembangan kawasan wisata serta pengoptimalisasikan elemen-elemen terkait yang berhubungan dengan kepariwisataan yang dimiliki oleh desa yang bersangkutan.

Desa Dopang, Kecamatan Gunungsari, Kabupaten Lombok Barat, Nusa Tenggara Barat merupakan salah satu desa yang didalamnya terdapat berbagai jenis kekayaan alam yang potensial untuk dikembangkan. Salah satunya adalah kekayaan alam yang berwujud wisata alam Bukit Korea yang terdapat dikawasan wisata Desa Dopang, di Dusun Dopang Utara yang terkenal dengan julukan Bukit Korea view Sunset.

Berdasarkan UU No. 10 tahun 2009 ( selanjutnya disingkat UU Kepariwisataan ) pasal I ayat (3) menyebutkan bahwa, pariwisata adalah berbagai macam kegiatan wisata dan didukung berbagai fasilitas serta layanan yang disediakan oleh masyarakat, pengusaha, pemerintah dan pemerintah daerah. Unsur-unsur pariwisata antara lain: (1). Unsur Geografis : menyuguhkan keindahan alam ciptaan Allah yang membuat turis bersyukur. (2). Unsur Historis : menyuguhkan sisa-sisa peninggalan sejarah yang membuat turis merasakan perjalanan waktu dan dapat mensyukuri kehidupannya. (3). Unsur kultural : menyuguhkan seni suatu daerah agar turis merasakan bahwa Allah sudah memberikan cipta, rasa dan karsa yang estetis pada manusia.

Selain optimasilasi kawasan wisata, adapun kegiatan pengembangan yang berkaitan dengan elemen-elemen wisata yaitu pemanfaatan sumberdaya Lokal setempat, pengelolaan sampah dan kebersihan lingkungan serta pembelajaran anak usia balita dan remaja berbasis alam dengan tujuan agar potensi wisata di Desa Dopang lebih berkembang dan maju dalam menunjangn keberhasilan ekonomi masyarakat dan meningkatkan PAD daerah (Desa). Hal ini yang membuat kami mengangkat tema Optimalisasi Pengembangan Kawasan wisata Bukit Korea Di Desa Dopang Kecamatan Gunung Sari Kabupaten Lombok Barat.

Optimalisai pengembangan di sini bermakna mulai dari proses penataan kawasan wisata, penambahan fasilitas penunjang wisata, pemantapan kelembagaan serta pembuatan media promosi berupa akun media sosial, sampai kegiatan puncak promosi berupa pengadaan ivent konser live music sebagai bentuk promosi wisata Bukit Korea, dalam hal ini anggota KKN 
bekerjasama dengan band local terkenal, Karang Taruna, pokdarwis serta masyarakat Desa dopang.

Karena itu kegiatan kuliah kerja nyata pemberdaya(KKN-P) ini bertujuan untuk membantu mengoptimalisasikan Pengembangan kawasan Wisata Bukit Korea sebagai kawasan wisata yang dapat memberikan manfaat bagi masyarakat dan lembaga pemerintah untuk meningkatkan perekonomian masyarakat dan mingkatkan PAD daerah Desa Dopang.

\section{ANALISIS PERMASALAHAN}

Dari hasil survey yang telah dilakukan didesa Dopang, bahwa kawasan wisata di bukit korea spenuhnya belum tertata dengan baik, yaitu dari segi penataan, fasilitas wisata, pemantapan kelembagaan serta kurangnya media promosi wisata yang belum dibentuk secara mantap, padahal untuk menjadi daerah wisata yang ramai dikunjungi harus memperbaiki permasalahan yang telah disebutkan.

\section{SOLUSI YANG DITAWARKAN}

\section{1. penataan taman bunga}

Proedur kerja sebagai berikut 1) pembuatan jadwal penataan, 2) pembelian alat dan bahan, 3) Mempersiapkan alat dan bahan 4) proses mendesgn tempat penataan 5) proses pembersihan lahan wisata serta pemotongan rumput 6) pembersihan lahan dan pemotongan rumput dilakukan setiap hari sampai minggu ke enam 7) penanaman Bungan serta penyemaian bibit Bungan tambahan 8) penyiraman dan perawatan bunga di lakukan $2 x$ dalam seminggu.

\section{2. penataan taman kincir}

Proedur kerja sebagai berikut 1) pembuatan jadwal penataan, 2) pembelian alat dan bahan, 3) Mempersiapkan alat dan bahan 4) proses mendesgn kincir 5) proses pemotongan kertas 6) proses pelipatan kincir angina 7) proses pembuatan tangkai kincir 8) proses pemasangan kincir pada tangkai 9) proses pemakuan kincir pada tangkai 10) proses pembersihan lahan tempat kincir 11) penancapan kincir dan pemasangan pelang taman kincir.

\section{3. penataan tempat duduk}

Proedur kerja sebagai berikut 1) pembuatan jadwal penataan, 2) Mempersiapkan alat dan bahan 3) pengangkutan alat dan bahan 4) proses penempatan tempat duduk yang strategis

\section{HASIL DAN PEMBAHASAN}

Dalam pelaksanaanya, setiap program kerja ditujukan sebagai penyaluran pengetahuan yang dimiliki oleh mahasiswa KKN baik melalui kegiatan fisik dan non fisik berupa sosialisasi untuk mengoptimalkan wawasan, dan kemampuan masyarakat yang bersangkutan, serta mempraktikan secara langsung, jadi dalam hal ini masyarakat Dopang diberikan pendekatan baik secara teoritis maupun praktis.

Dalam setiap pelaksanaan program kerja keterlibatan masyarakat didesa Dopang dioptimalkan, yang diharapkan dapat menciptakan masyarakat desa Dopang yang produktif, mandiri dan inovatif, serta mengembangkan jiwa bisnis (entrepreneur)dengan memanfaatkan kearifan lokal dari sektor agrikultur.

Pada kegiatan $\mathrm{KKN}$ ini terdapat tahapan dalam pelaksanaan program kerja sampai target semua program kerja terealisasi secara menyeluruh antara lain adalah :

1. penataan dan fasilitas objek wisata

Pertama, kegiatan penataan taman bunga dilakukan di lokasi Wisata Bukit Korea di lakukan oleh anggota KKN Unram, bekerjasama dengan Karang Taruna Desa Dopang. Bunga yang ditanam 
merupakan bunga yang sebelumnya telah mengalami proses pembibitan yang kemudian pindah tanam pada areal yang cocok untuk di tata, bunga yang di tanam merupakan bunga berjenis bunga matahari berwarna warni, selain itu adapula jenis bunga yang lainnya.

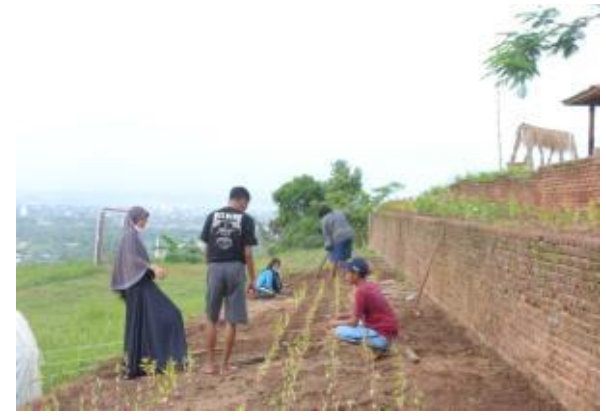

Gambar 1. Penataan taman bunga

Dalam pelaksanaannya penanaman bunga ini dilakukan pada minggu pertama dan rutin melakukan perawatan seperti penyiraman, gangguan dari hamadan gulma. Selain itu anggota KKN Unram juga melakukan pembibitan Bunga Matahari dimana nantinya bibit bunga ini dapat digunakan oleh pengelola wisata untuk menambah keanekaragaman tanaman bunga.

Kedua, kegiatan pembuatan spot foto taman kincir di bukit Korea di lakukan oleh anggota KKN Unram pada minggu ke 3. Adapun pembuatan taman kincir tersebut bertujuan untuk menambah wahana spot foto pendukung dari spot-spot foto yang lain seperti spot bintang, spot jembatan, spot ayunan tradisional, spot kupu-kupu dan spot pintu sunset.

Dalam pengerjaan taman kincir ini tahap pertama yang dilakukan adalah pembersihan lahan tempat, tahap pembuatan kincir dan tahappemasangan kincir angin. Pada tahap pembersihan lahan dilakukan selama 3 hari berturut-turut yaitu membersihkan rumput ilalang serta melakukan pengukuran luasan areal yang digunakan sebagai tempat kincir. Pada tahap pembuatan kincir yaitu digunakan kertas mika yang tahan pada kondisi panas dan tidak basah etika terkena air, dengan ukuran kertas $8 \mathrm{~cm} \times 8 \mathrm{~cm}$, kertas yang digunakan berwarna merah,kuning, hijau, biru. Pada tahap pemasangan kincir dalamhal ini luasan areal yang terpakai untuk pembuatan spot foto taman kincir adalah panjang : $5 \mathrm{~m} \times$ lebar :15m, dalam hal ini kincir angina menggunakan empat warna yaitu merah, kuning, hijau, biru. Adapun jarak sekat perbaris antar kincir adalah $40 \mathrm{~cm}$ sesama warna, sedangkan sekat antar kincir berbeda warna adalah $1 \mathrm{~m}$, total keseluruhan kincir yang terpajang adalah 116 untuk kincir berwarna merah, 116 kincir berwarna kuning, kincir berwarna kuning sejumlah 116 dan 116 kincir berwarna biru, sehingga total keseluruhan adalah 464 kincir angin.

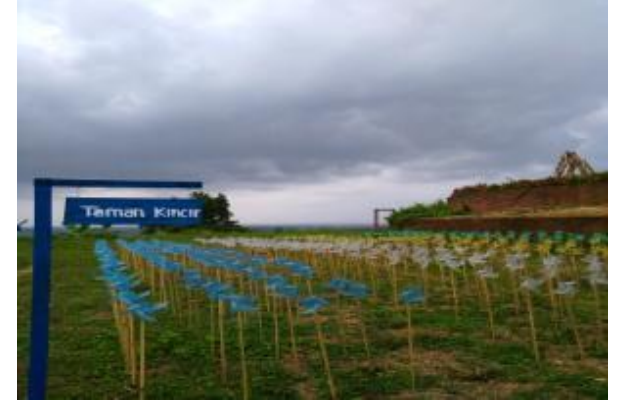

Gambar 2. Penataan taman kincir angin

Ketiga, kegiatan ini anggota KKn Unram bekerjasama bersama karang taruna serta warga untuk penambahan fasilitas tambahan serta penataan wisata bukit korea dalam rangka untuk menunjang fasilitas dan pelayanan wisatawan yang berkunjung. 


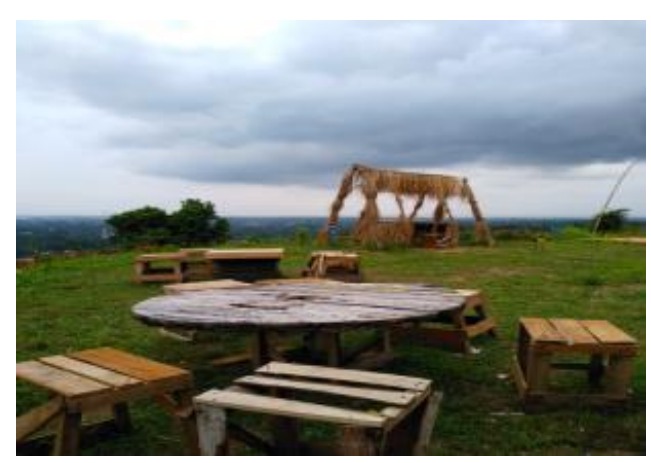

Gambar 3. Penataan tempat duduk

Pada proses penataan tempat duduk ini dilakukan secara gotong royong, meja yang digunakan terbuat dari gulungan kabel PLN dan sdangkan tempat duduk atau korsi terbuat dari papan yang dibuat sebelumnya oleh angota karang taruna, penataan dilakukan pada areal wisata yang strategis untuk beristirahat dan lokasi strategis untuk menikmati view pemandangan.

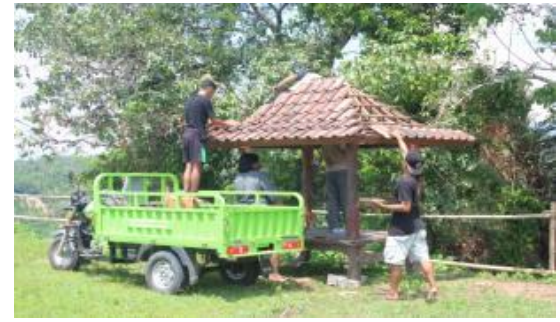

Gambar 4. Penambahan fasilitas gazebo

Sedangkan penambahan fasilitas lainnya berupa gazebo dan pembuatan toilet di kerjakan secara gotong royong dengan anggota KKN, karang Taruna dan Warga, gazebo dan toilet adalah bahan yang telah dipersiapkan oleh pihak karang taruna, dalam pengerjaannya gazebo dan toilet di angkut menggunakan mobil pickup dan di tempatkan berdasarkan tempat yang strategis.

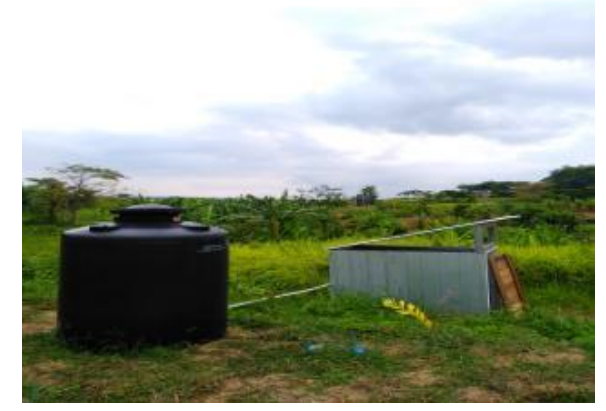

Gambar 5. Penambahan fasilitas toilet

Kelima, kegiatan pembuatan plang penunjuk daerah wisata Bukit Korea dilakukan oleh anggota tim KKN Unram, dibantu oleh karang taruna Desa Dopang. Adapun plang-plang yang dibuat tersebut menyakup penunjuk arah menuju objek wisata Bukit Korea. Plang tersebut berbentuk anah panah yang terbuat dari kayu usuk, dan dicat dengan cat kayu, sebagai penunjuk arahnya, warna biru sebagai dasarnya dan warna putih untuk tulisannya, serta digunakan pula tiang kayu sebagai penyangganya. Pemasangan pelang dilakukan disetiap persimpangan jalan yang ada di desa Dopang. Pembuatan pelang-pelang tersebut membutuhkan waktu 3 hari, manfaat dan hasil guna dapat dimanfaatkan oleh pengunjung objek wisata yang datang atau berasal dari luar desa Dopang sehingga pengunjung tidak lagi mengalami kesulitan untuk menuju objek wisata. 


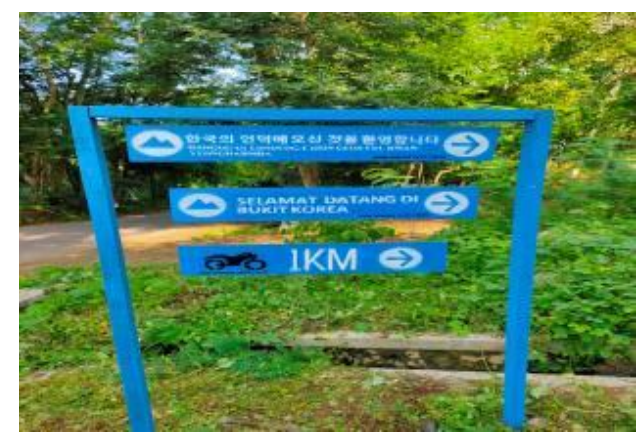

Gambar 6. Pasilitas plang petunjuk arah

Pembuatan ini bertujuan untuk memudahkan wisatawan menuju ke tempat wisata agar tidak tersesat. Ketika seseorang hendak menuju suatu tempat maka hal pertama yang diperhatikan adalah papan petunjuk arah. Papan petunjuk arah berfungsi untuk memberikan arah ke suatu tempat yang biasanya terdiri atas beberapa arah seperti ke depan, kanan, dan kiri. Apabila tidak ada papan petunjuk arah maka seseorang dapa tersesat selama perjalanan. Oleh karena itu, melalui Kuliah Kerja Nyata (KKN) kami membuat papan petunjuk arah yang terbuat dari kayu yang di cat warna biru dan putih.

Keenam, tempat sampah adalah salah satu sarana untuk membuat lingkungan menjadi bersih, tertib, tertata dan terlihat indah. Kebersihan seringkali menjadi salah satu masalah yang menggangu dikawasan wisata, yang tadinya anda bisa menikmati pemandangan yang indah, tetapi karena sampah keindahan tempat wisatapun berkurang. Akhirnya pengunjungpun menyalahkan pihak pengelola, tak jarang juga menyalahkan pemerintah atas ketidaknyamanan yang mereka alami tersebut. Dengan alasan tempat sampah jauh, para pengunjungpun dengan sesuka hati membuang sampah dimana saja. Jika ingin terlihat mereka menyelipkannya di daerah yang tak mudah dijangkau mata. Masalah kebersihan dan sampah ini sebenarnya sederhana. Jika ada kesadaran membuang sampah pada tempatnya atau menyimpannya terlebih dahulu sampai ditemukan tempat sampah. Menyadari pentingnya menumbuhkan rasa cinta kebersihan untuk menjaga tempat wisata seperti kegiatan membuat tempat sampah di lokasi wisata.

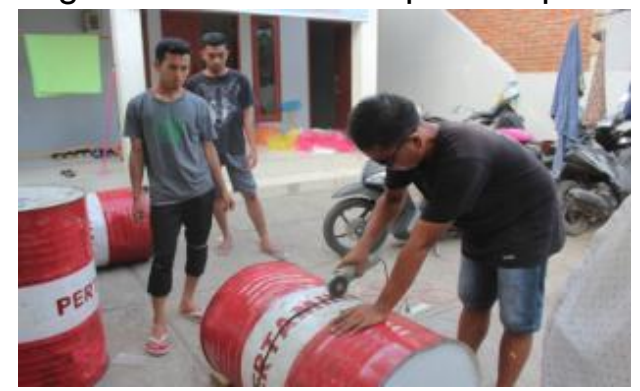

Gambar 7. Fasilitas penambahan tong sampah

Ketujuh, langkah pertama yang dilakukan adalah dengan melakukan pembersihan di lokasi wisata. Kegiatan ini dilakukan di minggu pertama pelaksanaan KKN. Bukit Korea sendiri di bersihkan selama 4 hari karena banyak semak belukar dan ilalang tumbuh di lokasi tersebut. Pemungutan sampah, penyabitan tanaman liar, merapikan tanaman, pengumpulan bekas penyabitan tanaman liar, bertujuan untuk menjaga lingkungan agar tetap terawat sehingga terbebas dari sampah dan tanaman liar yang mengganggu pemandangan dan mengurangi nilai keindahan. 


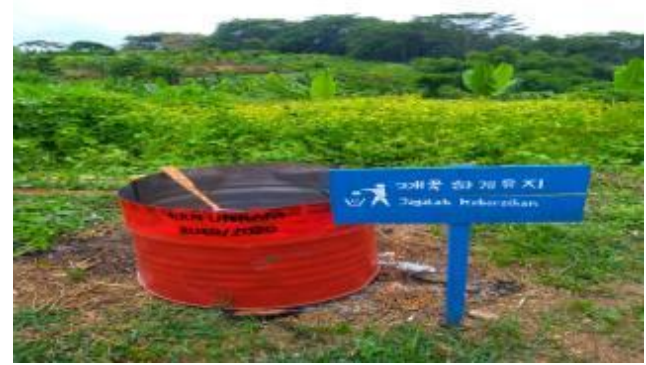

Gambar 8. Fasilitas tong sampah

Pemasangan tempat sampah dilakukan diberbagai titik lokasi daerah wisata. Di Bukit korea dipasang 4 tempat sampah. Pembuatan desain, menyediaan alat dan bahan, pembuatan tempat sampah, dan penempatan tempat sampah dengan tujuan meminimalisir sampah yang ada di sekitar sehingga tempat wisata terlihat rapi, bersih, dan asri. Adanya tempat sampah sebagai upaya untuk menjaga lingkungan agar terbebas dari tumpukan sampah yang mengurangi nilai kebersihan.

Kedelapan, penataan kembali Bukit Korea salah satunya adalah pembuatan dekorasi spotspot foto yang booming pada saat ini. Area foto sering kali diburu oleh anak remaja saat ini. Selain itu tempat foto, yang dikelilingi pemandangan alam seperti bukit korea ini, menjadi salah satu tujuan mereka.

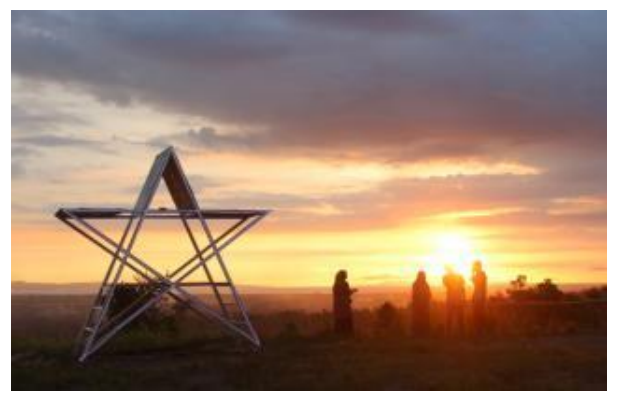

Gambar 9. Dekorasi spot foto

Dekorasi bertujuan untuk menghias sesuatu agar tampak tertata dengan indah, sehingga menambah daya tarik wisatawan. Untuk itu sebelum pemasangan dan penataan kami melakukan pendekoran terlebih dahulu.

Kesembilan, desain papan objek wisata, penyediaan alat dan bahan, pembuatan dan pemasangan papan nama objek wisata bertujuan untuk mempermudah dan memperjelas wisatawan untuk mengetahui lokasi dari wisata di Desa Dopang.

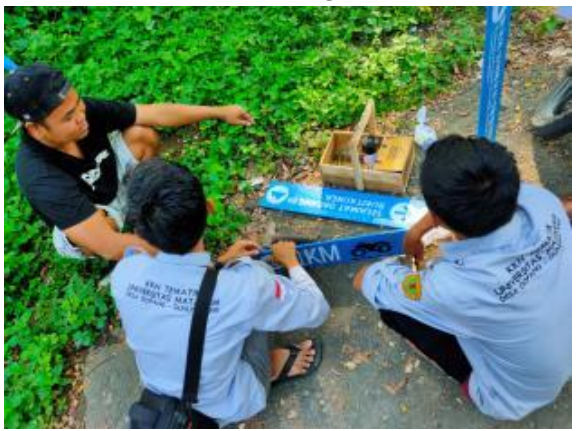

Gambar 10. Papan nama wisata bukit korea 
Kesepuluh, pembuatan medsos bertujuan sebagai sarana atau media untuk mempromosikan dan memperkenalkan objek wisata yang ada di Desa Dopang. Karena seperti yang kita ketahui pada era modern sekarang ini media sosial sangat efektif dan efisien digunakan untuk mempromosikan wisata. Untuk itu kami harapkan dengan pembuatan media sosial ini dapat meningkatkan jumlah wisatawan yang datang berkunjung ke wisata yang ada di Desa Dopang.

\section{KESIMPULAN}

Dari berbagai program kerja yang telah dijalani yang berfokus pada sektor Pariwisata maka dapat disimpulkan bahwa optimaliasis pengembangan kawasan bukit Korea berupa penataan, penambahan fasilitas, pemantapan kelembagaan dan sosialisai pengelolaan wisata bukit Korea serta pengembangan element terkait berupa pemanfaatan sumberdaya lokal, menjaga kesehatan dan lingkungan serta belajar bersama alam, maka dapat dikatakan memberikan manfaat yang besar bagi lembaga pengelola wisata, serta masyarakat desa sehingga masyarakat mulai terbangun untuk lebih sadar terhadap pengembangan wisata terutama kawasan wisata bukit Korea. Bentuk peratian masyarakat terlihat dari semua kegiatan KKN Unram di dukung sepenuhnya dan selalu terlibat dalam Pengembangan Wisata Bukit Korea.

\section{REFERENSI}

Muljadi A.J, 2009, kepariwisataan dan perjalanan, rajawali pres, Jakarta.

Profil Desa dan Kelurahan Desa Dopang. 2017. Pedoman Penyusunan dan Pendayagunaan Data Profil Desa dan Kelurahan. Badan Pemberdayaan Masyarakat Dan Pemerintahan Desa( BPMPD) Provinsi Nusa Tenggara Barat.

Samorn, M.C.L. Sales, and S, Phunsiri. 2002. Solid waste recycling, Disposal and Management in Bangkok. J Environ. Res. 28:106112.

Sumardi, M. 2001. Kemiskinan Daerah Urban. Rajawali. Jakarta.

Malo, M. 2003. Metode Penelitian Sosial. Pusat Penertiban Universitas Terbuka. Jakarta.

Laporan KKN Tematik Desa Dopang Periode Agustus-September 2019. 